\title{
A STUDY OF BIODIVERSITY AND WATER QUALITY BY ANALYSING AQUATIC MACROINVERTEBRATES IN THE PASOCHOA WILDLIFE REFUGE, ECUADOR
}

\author{
Bersosa, F. ${ }^{1}$ - CALDERÓN, V. ${ }^{2}-$ SANCHEZ, R. ${ }^{3 *}-$ SARZOSA, M. ${ }^{4}-$ MÁtyÁs, B. ${ }^{3}$ \\ ${ }^{I}$ Grupo de Investigación en Ecología y Gestión de los Recursos Naturales (GIERENA), \\ Universidad Politécnica Salesiana, Rumichaca y Morán Valverde s/n, Quito, Ecuador \\ (phone: +593-2-396-2900; fax: +593-2-396-2800) \\ ${ }^{2}$ Universidad Politécnica Salesiana, Rumichaca y Morán Valverde s/n, Quito, Ecuador \\ (phone: +593-2-396-2900; fax: +593-2-396-2800) \\ ${ }^{3}$ Grupo de Investigación en Ciencias Ambientales (GRICAM), Universidad Politécnica \\ Salesiana, Rumichaca y Morán Valverde s/n, Quito, Ecuador \\ (phone: +593-2-396-2900; fax: +593-2-396-2800) \\ ${ }^{4}$ Ministerio del Ambiente, Calle Madrid 1159 y Andalucía, Quito, Ecuador \\ (phone: +593-2-398-7600) \\ *Corresponding author \\ e-mail: rsanchezp@ups.edu.ec; phone: +593-99-985-5457
}

(Received $8^{\text {th }}$ Nov 2018; accepted $5^{\text {th }}$ Mar 2019)

\begin{abstract}
The Province of Pichincha, Ecuador is home to the calderas and flanks of the Pasochoa volcano, where the Pasochoa Wildlife Refuge (RVSP for its Spanish acronym) is located. This area is one of the few places that conserves some of the most important remnants of the Andean native forest. This study seeks to determine the biodiversity and water quality of the Pasochoa Wildlife Refuge by studying its aquatic macroinvertebrates. The data for this work were obtained from five sampling points located between the caldera and outside the RVSP. This effort was carried out along the stream that descends from the Pasochoa volcano at an altitude of 3014 meters above sea level (masl) to 2667 masl. Water samples were also obtained for a physical-chemical analysis. Preliminarily, a total of 6149 invertebrates, corresponding to 3 phyla, 10 orders and 36 families, were captured as indicators of water quality. The most abundant phylum was Arthropoda, with 6130 individuals. Additionally, specimens of annelids and mollusks were recorded. The greatest abundance was recorded for the families of Elmidae (Coleoptera) and Leptoceridae (Trichoptera), with 2059 and 1071 individuals, respectively. According to the families that indicate water quality, it fluctuates between very good to regular in PMM-01, which is an area with anthropic influence.
\end{abstract}

Keywords: environmental indicators, water quality, species richness, abundance, environmental quality

\section{Introduction}

Modelling the environment and water resources are essential to improve and protect water quality (Eurie et al., 2015; Forio et al., 2016). Today, water monitoring has become particularly important due to the increasing human activity that often leads to water quality deterioration (Yillia et al., 2008; Holguin-Gonzalez et al., 2013; Kibena et al., 2014). Selecting the right indicators for monitoring has become essential and often the most challenging task of environmental studies and applied conservation science (Game et al., 2016). We have chosen macroinvertebrates for determining water quality considering that they are well-known indicators in environmental monitoring and assessment worldwide (Forio et al., 2016). 
The Pasochoa Wildlife Refuge (RVSP) is located in the caldera and in the flanks of the Pasochoa volcano, in the province of Pichincha, Ecuador. This area is one of the few places that conserves some of the most important remnants of the Andean native forest.

According to our bibliographic review, quantitative-type floristic investigations have been carried out within the protected area, such as those by Valencia and Jorgensen (1992), while other studies have consisted of rapid sampling where physical backups are not available. In terms of fauna, bird lists have been compiled by Sierra (1996), and the baseline list was recorded by Fundación Natura (1990). Studies referring to both terrestrial and aquatic insects are practically nonexistent for the sector. According to the map of vegetal coverage by the MAE (2013), the vegetal formation is a high-altitude evergreen mountain forest in the northern part of the Eastern Cordillera of the Andes. Its altitude range is from 3000 to 3700 masl, and the grassland of the moors ranges from 3400 to 4300 masl. The area has an average annual rainfall of $1200 \mathrm{~mm}$, an average annual temperature of $10^{\circ} \mathrm{C}$ and a relative humidity that is almost higher than $80 \%$ (Valencia and Jørgensen, 1992).

In this study, aquatic macroinvertebrates were used as indicators of environmental quality. Aquatic macroinvertebrates have received much attention in studies regarding the ecosystems of running waters because they are transformers and integrators of allochthonous organic matter (leaves, seeds, branches, fallen trunks, etc.), the main inflows of energy to the fluvial systems and useful biological indicators.

\section{Materials and methods}

The Pasochoa Wildlife Refuge is located in the Province of Pichincha, Cantón Mejía, in the parish of Uyumbicho, Ecuador. It contains 520 hectares, which are covered mostly by Andean forest and, to a lesser extent, by herbaceous moorland. For the sampling points, the area of the caldera was prioritized because it is a pristine area, has been conserved and contains remnants of a mature forest. The second sampling point corresponded to the area outside the wildlife refuge where anthropic influence exists due to the presence of livestock and pastures. Then, the two areas were compared and evaluated. The data for this work were obtained from five sampling points along the stream that descends from the Pasochoa volcano from an altitude of 3014 to 2667 masl. The sampling points can be seen in Figure 1 (López-López and Sedeño-Díaz, 2014).

The macroinvertebrates were collected through a "Surber" network in five sampling points (Fig. 1) along a $100 \mathrm{~m}$-long transect according to the proposal of Roldán (2003) (Brito and Pinto, 2014). At each sampling point, we examined the riverbed of each body of water for a lapse of one minute to capture the existing macroinvertebrates, covering all possible microhabitats (riparian vegetation, sandy areas, rocky areas and algae). In addition, the ecological quality protocols for Andean rivers that were proposed by Encalada et al. (2011) were applied (Damanik-Ambarita, 2016; Carter, 2017; Mariadoss and Abril, 2015).

The samples were cleaned to later extract the macroinvertebrates and deposit them in correctly labeled plastic containers with $70 \%$ alcohol. Field work was executed following the rules and regulatory guidelines outlined by the Environment Ministry's research permit.

To determine aquatic invertebrates, which were deposited in the aforementioned containers, the specimens were separated and identified at the family taxonomic level according to the protocols proposed by Encalada et al. (2011). To identify the 
invertebrates, we used the taxonomic keys of Fernández and Dominguez (2009). The invertebrate collections will be displayed in the Gustavo Orcés Natural History Museum at the Escuela Politécnica Nacional, under patent No. 04-2014-FAU- DPAP-MA (Knowl, 2016; Stancheva and Seath, 2016).

The analyses related to the abundance, diversity, and species accumulation curves were performed according to Colwell (2006) and Oksanen, 2015 using the EstimateS 8.2.0 programs and PAST (Paleontological Statistics version 1.12) according to Hammer et al. (2003).

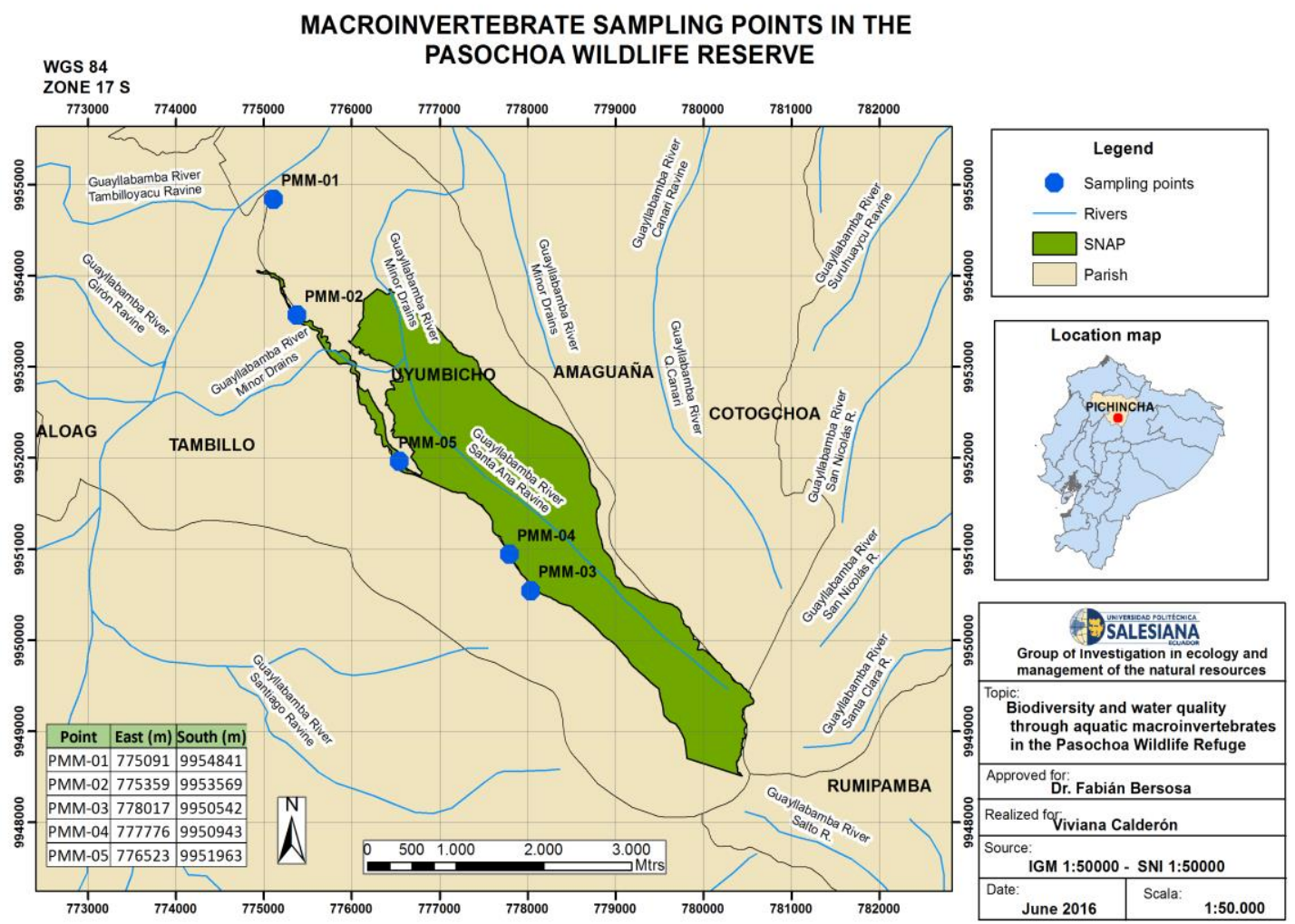

Figure 1. Sampling points for macroinvertebrates in the Pasochoa Wildlife Reserve. "PPM$01 "=$ Point 1; "PPM-02" = Point 2; "PPM-03" = Point 3; "PPM-04" = Point 4; "PPM$05 "$ = Point 5; "Este" = East; "Sur" = South. Legends: "Puntos de muestro" = Sampling point, marked with blue dots; "Rios" = Rivers, marked with green line;

"Parroquias" = Parishes

The analyzed parameters were divided into two groups. The first group is related to finding out the level of intromission of human effluents, such as gray and black waters, discharges from tourism or agriculture, and so on. Here, we measured the 5-day dissolved oxygen, Biochemical Oxygen Demand (BOD5), phosphorus, ammonia, nitrate and nitrite, the last three of which are indicators of pollution temporality (Cheeme, 2018). The second group of indicators focused on change in water quality due to human or natural causes. The indicators used were $\mathrm{pH}$, calcium hardness, turbidity and total solids. The presence of calcium hardness, increased BOD5 and decreased dissolved oxygen could be the result of diffuse soil contamination from fertilizers (Schahrakane, 2018). 


\section{Results}

A total of 6149 invertebrates were captured, corresponding to 3 phyla, 10 orders and 36 families, that indicate the water quality. The most abundant phylum was Arthropoda, with 6130 specimens. Additionally, specimens of annelids and mollusks were recorded (Table 1).

The greatest abundance was recorded in the families of Elmidae (Coleoptera) and Leptoceridae (Trichoptera), with 2059 and 1071 individuals, respectively. The greatest abundance was recorded in Point 5.

Table 1. Diversity and abundance

\begin{tabular}{c|c|c|c|c|c}
\hline Parameter & Point 1 & Point 2 & Point 3 & Point 4 & Point 5 \\
\hline Taxa_S & 11 & 20 & 20 & 27 & 29 \\
Individuals & 197 & 253 & 465 & 2468 & 2766 \\
Dominance_D & 0.3141 & 0.1245 & 0.1764 & 0.2585 & 0.2303 \\
Simpson_1-D & 0.6859 & 0.8755 & 0.8236 & 0.7415 & 0.7697 \\
Shannon_H & 1383 & 2.35 & 1999 & 1792 & 1888 \\
\hline
\end{tabular}

The determination of the quality of water in the sector by means of physical chemical parameters has not been done previously, but as regards the diversity in the present study, 3 phyla, 10 orders and 36 families were found in front of the study by Gallegos, 2013, which mentions 4, 13 and 34 respectively

Low values of dissolved oxygen were observed for all points, which are not due to temperature but to the existence of an organic load from three thousand meters high. This is corroborated by the BOD5 measurements that are accentuated in Point 4, where it reached $36 \mathrm{mg} / \mathrm{l}$. With these levels of dissolved oxygen, fish cannot exist. From Point 2 onwards, there is a continuous presence of ammonia, which causes the depletion of dissolved oxygen and an increase in the nitrogen-bearing BOD5, which is oxidized slowly into nitrate and quickly into nitrite.

The increase in BOD5 and calcium hardness and the decrease in dissolved oxygen demonstrate the diffused intrusion of runoff water from crops with agrofertilizers.

The $\mathrm{pH}$ is basic, probably due to the type of riverbed in the upper part of the volcano, which decreases downstream. Turbidity increases as the water descends; the same is true for solids in the water, probably because of erosion and an increase in the organic load.

Current water quality does not present levels of eutrophication, but its decontamination is required for the water habitable by fish, and safe for human use. The results of the analyses, location and distance between the points are presented in Table 2. 
Table 2. Results of the water quality analysis

\begin{tabular}{c|c|c|c|c|c}
\hline Parameter & Point 1 & Point 2 & Point 3 & Point 4 & Point 5 \\
\hline Altitude (masl) & 3,014 & 2,995 & 2,864 & 2,718 & 2,667 \\
Length from the previous point (m) & 0 & 464 & 1,618 & 1,983 & 1,339 \\
Dissolved oxygen (mg/l) & 2.3 & 2.3 & 3 & 1 & 0.9 \\
BOD5 (mg/l) & 1.9 & 0.9 & 2.16 & 36 & 7.2 \\
Total phosphorus (mg/l) & 0.4 & 0.4 & 0.4 & 0.5 & 0.4 \\
Ammonia (mg/l) & 0 & 0.01 & 0.09 & 0.07 & 0.57 \\
Nitrate (mg/l) & 0 & 0 & 0 & 0 & 0 \\
Nitrite (mg/l) & 14 & 10 & 13 & 9 & 19 \\
pH & 8.35 & 8.82 & 8.5 & 8.1 & 7.41 \\
Calcic hardness (mg/l) & 0.38 & 0.63 & 1.09 & 0.79 & 1.3 \\
Turbidity (NTU) & 1.5 & 2.29 & 0.93 & 3 & 4.28 \\
\hline Total solids (mg/l) & 0.06 & 0.06 & 0.07 & 0.08 & 0.1 \\
\hline
\end{tabular}

\section{Conclusions and recommendations}

Values of BOD5 vary between $0.9-36 \mathrm{mgL}^{-1}$ in our study that are comparable to other study (Naciph, 2016) findings (BOD5 vary between 5-40 $\mathrm{mgL}^{-1}$ ) where San Pedro River was analysed. It is reassuring that the diversity and abundance values in our study are significantly higher than the values in Naciph's study where the same method (Encalada et al., 2011) was applied for specimens separation and for family taxonomic level identification. In our study 36 families were detected, while in Naciph's study only 12. This is due to the sad fact that San Pedro River is highly contaminated (FONAG, 2011) and can not be used for irrigation without pre-treatment (Naciph, 2016).

To aid reader understanding in the topic our preliminary study should be extended to other study areas, such as the lower part of the volcano, where areas of influence, such as cattle, urbanisation and plantations, exist.

According to the families that indicate the quality of water, the water quality fluctuates between very good to regular in Point 2, which is an area with anthropic influence. The current water quality does not present levels of eutrophication, but decontamination is required for the water to be safely used by humans.

\section{REFERENCES}

[1] Brito, C., Pinto, F. (2014): Biological monitoring using macroinvertebrates as bioindicators of water quality of Maroaga Stream in the Maroaga Cave System, Presidente Figueiredo, Amazon, Brazil. - International Journal of Ecology. Article ID: 308149.

[2] Carter, J., Resh, J., Morgan, J. (2017): Macroinvertebrates as Biotic Indicators of Environmental Quality. - In: Hauer, F. R., Lamberti, G. (eds.) Methods in Stream 
Ecology. Third Ed. Vol. 2: Ecosystem Function. Academic Press, Cambridge, MA, pp. 293-318.

[3] Cheema, P., Pal, S., Akepati, S., Leena, G., Kaur, D. (2018): Multivariate analysis of wastewater quality of different rural human settlements in Punjab (India). Environmental Engineering \& Management Journal (EEMJ) 17(2): 371-380.

[4] Colwell, R. K. (2006): Estimates, Statistical Estimation of Species Richness and Shared Species from Samples Version 8.0. User's Guide and Application. http://chao.stat.nthu.edu.tw.

[5] Damanik-Ambarita, M. N., Lock, K., Boets, P., Everaert, G. (2016): Ecological water quality analysis of the Guayas river basin (Ecuador) based on macroinvertebrates indices. - Limnologica 57: 27-59.

[6] Encalada, A., Riera, M., Rios, B., Garcia, N., Prant, N. (2011): Simplified protocol and guide for evaluating the ecological quality of Andean rivers (Spanish: Protocolo Simplificado y guía de evaluación de la calidad ecológica de ríos Andinos). - CERA-S: USF, AECID, UB, FONAG, Quito.

[7] Eurie, M. A., Landuyt, D., Bennetsen, E., Lock, K., Tien, T. H., Damanik, M. N., Sasha, P. L., Boets, P., Everaert, G., Dominguez-Granda, L., Goethals, P. L. M. (2015): Bayesian belief network models to analyse and predict ecological water quality in rivers. - Ecological Modelling 312: 222-238.

[8] Fernández, H. R., Dominguez, E. (2009): Guide for the Determination of South American Benthic Arthropods. (Spanish: Guía para la determinación de los artrópodos bentónicos sudamericanos). - Universidad Nacional de Tucumán, Argentina.

[9] FONAG (2011): Information about the Guayllabamba River Basin (Información de la Cuenca del Río Guayllabamba). - http://visor.infoagua-guayllabamba.ec/visor/index.html (accessed: 20 August 2016).

[10] Forio, M. A. E., Van Echelpoel, W., Dominguez-Granda, L., Mereta, S. T., Ambelu, A., Hoang, T. H., Boets, P., Goethals, P. L. M. (2016): Analysing the effects of water quality on the occurrence of freshwater macroinvertebrate taxa among tropical river basins from different continents. - AI Communications 29: 665-685.

[11] Fundación Natura. (1990): Fundación Natura.- Quito s.e. Publishing, Quito

[12] Game, E. T., Bremer, L. L., Calvache, A., Moreno, P. H., Vargas, A., Rivera, B., Rodriguez, L. M. (2016): Fuzzy models to inform social and environmental indicator selection for conservation impact monitoring. - Conservations Letters 11: e12338.

[13] Hammer, O., Harper, D. A. T., Ryan, P. D. (2003): PAST: Paleontological Statistics. Version 1.12. - http://palaeo-electronica.org/2001_1/past/issue1_01.htm.

[14] Knowl, M. (2016): Benthic soft-bodied algae as bioindicators of stream water quality. Aquat. Ecosyst. 417: 15.

[15] López-López, E., Sedeño-Díaz, J. (2014): Biological Indicators of Water Quality: The Role of Fish and Macroinvertebrates as Indicators of Water Quality. - In: Armon, R. H., Hanninen, H. (eds.) Environmental Indicators. Springer, Dordrecht, pp. 643-661.

[16] MAE

(2013): http://suia.ambiente.gob.ec/documents/10179/346525/ESTADISTICAS+DE+PATRIMO NIO+FINAL.pdf/b36fa0a7-0a63-4484-ab3e-e5c3732c284b.

[17] Mariadoss, S., Abril, R. (2015): Water quality assessment of Piatua River using macroinvertebrates in Puyo, Pastaza, Ecuador. - American Journal of Life Sciences 3(3): 167-174.

[18] Naciph, K. A. (2016): Water Quality Analysis of the San Pedro River and Proposal of a Water Treatment Design for its Use as a Water Source for a Communitarian Irrigation Project. - Universidad San Francisco De Quito USFQ (Quito, 12 de diciembre de 2016).

[19] Oksanen, J. (2015): Vegan: Ecological Diversity. - https://cran.rproject.org/web/packages/vegan/vignettes/diversity-vegan.pdf (accessed: 21 Apr 2016.

[20] Roldán, G. (2003): Bioindicators of Water Quality in Colombia (Spanish: Bioindicadores de la calidad de agua en Colombia). - Uso del BMWP/Col. del Departamento de 
Antioquía. Colección Ciencia y Tecnología, Universidad de Antioquia, Bogotá, Colombia.

[21] Schahrakane, Y., Tazi, O., Idali, H., Benjeloun, N. (2018): Physicochemical and microbiological study of the Ourika Watershed hydrographic network (MarrakechMorocco region). - Advances in Environmental Sciences, Cluj-Napoca Tomo 10(3): 168.

[22] Sierra, R. (1996): Deforestation in the Northwest of Ecuador 1983-1993. (Spanish: La deforestación en el Noroccidente del Ecuador 1983-1993). - EcoCiencia, Quito, Ecuador.

[23] Stancheva, R., Seath, R. (2016): Benthic soft-bodied algae as bioindicators of stream water quality. - Knowl. Manag. Aquat. Ecosyst. 417: 15.

[24] Valencia, R., Jorgensen, P. (1992): Composition and structure of a humid montane forest on the Pasochoa Volcano, Ecuador. - Nord. Journal Bot. 12: 239-247.

\section{APPENDIX}

Abundance of the different families within the sampling points

\begin{tabular}{|c|c|c|c|c|c|c|c|}
\hline Order & Family & Point 1 & Point 2 & Point 3 & Point 4 & Point 5 & $\begin{array}{c}\text { Number } \\
\text { of } \\
\text { individual } \\
\mathrm{s}\end{array}$ \\
\hline Oligochaeta & N.d & 2 & 16 & 1 & & & 19 \\
\hline Amphipoda & Hyalellidae & 3 & 50 & & 30 & 31 & 114 \\
\hline Coleoptera & Dytiscidae & & 1 & & 3 & 1 & 5 \\
\hline \multirow{16}{*}{ Diptera } & Elmidae & 1 & 6 & 80 & 1006 & 966 & 2059 \\
\hline & Ptilodactylidae & & 3 & 2 & 1 & 3 & 9 \\
\hline & Scirtidae & 1 & 26 & 3 & 29 & 11 & 70 \\
\hline & Staphylinidae & & & & 6 & 3 & 9 \\
\hline & Blepharoceridae & & & & 2 & 4 & 6 \\
\hline & Ceratopogonidae & 4 & 51 & 22 & 50 & 50 & 177 \\
\hline & Chironomidae & 36 & 25 & 124 & 117 & 163 & 465 \\
\hline & Culicidae & & & 1 & & & 1 \\
\hline & Dixidae & & & & & 1 & 1 \\
\hline & Empididae & & 1 & & & & 1 \\
\hline & Limoniidae & & 4 & & 4 & 8 & 16 \\
\hline & Muscidae & & & & 1 & 5 & 6 \\
\hline & Psychodidae & & 1 & & 4 & 6 & 11 \\
\hline & Simuliidae & 83 & 29 & 76 & 30 & 16 & 234 \\
\hline & Tabanidae & & & 5 & 41 & 35 & 81 \\
\hline & Tipulidae & 2 & 14 & 25 & 678 & 368 & 1087 \\
\hline
\end{tabular}




\begin{tabular}{|c|c|c|c|c|c|c|c|}
\hline \multirow{3}{*}{ Ephermeroptera } & Baetidae & 63 & 13 & 96 & 121 & 122 & 415 \\
\hline & Leptohyphidae & 1 & & 1 & 35 & 69 & 106 \\
\hline & Leptophlebiidae & 1 & & & 1 & 1 & 3 \\
\hline Heteroptera & Veliidae & & 1 & & & & 1 \\
\hline Hydracarina & N.d & & 2 & & & & 2 \\
\hline Plecoptera & Perlidae & & 1 & 1 & 12 & 26 & 40 \\
\hline \multirow{11}{*}{ Trichoptera } & $\begin{array}{c}\text { Anomalopsychid } \\
\text { ae }\end{array}$ & & 5 & 2 & 19 & 28 & 54 \\
\hline & Glossosomatidae & & \multirow{10}{*}{2} & \multirow{5}{*}{$\begin{array}{l}2 \\
5 \\
1\end{array}$} & 1 & 3 & 4 \\
\hline & Helicopsychidae & & & & 9 & 7 & 18 \\
\hline & Hidropsychidae & & & & & & 5 \\
\hline & Hydrobiosidae & & & & 1 & & 2 \\
\hline & Hydropsychidae & & & & 6 & 9 & 15 \\
\hline & Hydroptilidae & & & 4 & & 14 & 18 \\
\hline & Leptoceridae & & & 13 & 256 & 800 & 1071 \\
\hline & Limnephilidae & & & & 1 & 11 & 12 \\
\hline & Odontoceridae & & & 1 & & & 1 \\
\hline & Philopotamidae & & & & 4 & 4 & 8 \\
\hline Veneroidea & N.d & & 2 & & & & 2 \\
\hline $\begin{array}{c}\text { Basommatophor } \\
\text { a }\end{array}$ & Limnaeidae & & & & & 1 & 1 \\
\hline \multicolumn{2}{|c|}{ Total: } & 197 & 253 & 465 & 2468 & 2766 & 6149 \\
\hline
\end{tabular}

